\title{
CARTA DE PRESENTACIÓN
}

Para la Facultad de Ciencias Económicas y Empresariales de la Universidad Rafael Landivar es grato presentar la edición número veintidós de la Revista Académica $E C O$, que tiene como objetivo difundir investigaciones de temas relativos a las ciencias económicas.

En esta edición, la revista contiene artículos relativos a las neurociencias y su creciente aplicación en el sector empresarial, exponiendo de qué manera el conocer el funcionamiento del cerebro humano ha apoyado al desarrollo de propuestas efectivas para la solución de problemas comerciales.

El primer artículo analiza la evolución de la aplicación de las neurociencias, tanto a nivel teórico como práctico, en el ámbito del marketing y cómo ello impacta en la generación de estrategias mercadológicas innovadoras.

En el segundo artículo, el autor propone la neuronegociación como un método efectivo para gestionar las emociones y generar una comunicación efectiva entre las partes, lo que permite lograr exitosamente los objetivos establecidos. Plantea que un óptimo manejo de la inteligencia emocional y racional, la intuición, la asertividad y el conocimiento profundo de las fortalezas y debilidades personales, son ingredientes esenciales para el desarrollo de una estrategia que permita una negociación trascendente.

En la actualidad, el mundo avanza a un ritmo vertiginoso, lo que ha originado una constante: el cambio. Esta continua transformación evidencia la necesidad de gestionar las organizaciones a través de modelos no lineales. El tercer artículo expone que los negocios más exitosos son liderados por personas con un alto grado de intuición y creatividad, por lo que sugiere al empresario y al emprendedor desarrollar el pensamiento no lineal, para enfrentar los retos empresariales de hoy.

¿Existe una relación entre la dominancia cerebral y la elección de la profesión? El autor del cuarto artículo utilizó una prueba elaborada con base en los lineamientos establecidos por Herrmann en 1994, para identificar el estilo de pensamiento dominante en más de novecientos estudiantes universitarios. El objetivo del estudio es determinar si la forma de pensar, crear o aprender, así como capacidad analítica, de planificación y administración, comunicación y emprendedora de los estudiantes coincide con las exigencias del entorno laboral que requiere la profesión elegida. 
Cerramos esta edición con un artículo que analiza la conducta del consumidor en el campo de la economía, desde un enfoque que permite mejorar la comprensión del proceso que siguen las personas para tomar decisiones, al considerar que estas no están necesariamente basadas en la racionalidad.

Confiamos que la selección de textos sea de interés y agrado del lector.

Consejo Editorial

Facultad de Ciencias Económicas y Empresariales

Universidad Rafael Landívar

\section{Alcance editorial}

La Revista Académica ECO de la Facultad de Ciencias Económicas y Empresariales de la Universidad Rafael Landívar, recibe artículos inéditos, que no se encuentren en proceso de evaluación o publicación por parte de otra revista, que aporten nuevo conocimiento a la disciplina, ajustándose a la versión de estilo editorial más reciente de la Asociación de Psicología Americana (APA).

Si desea postular artículos comunicarse con:

Mgtr. Paola Soto Arrivillaga

Departamento de Maestrías

Universidad Rafael Landívar

PBX: (502) 2426-2626, extensión: 2350

pvsoto@url.edu.gt

Sitio electrónico de la revista: http://recursosbiblio.url.edu.gt/CParens/Revista/ECO/

Otras ediciones: http://biblioz.url.edu.gt/Revistas/ECO/ECO.php 